\title{
Asthma mortality and death certification in Northern Ireland
}

\author{
S C Wright, A E Evans, D G Sinnamon, J MacMahon
}

\begin{abstract}
Background - Asthma mortality has been rising in many western countries for largely unknown reasons. One cause could be change in certification practice. This study was designed to investigate the accuracy of death certification in Northern Ireland for the years 1981-4 and, in addition, to assess the reliability of trends observed in asthma death registration from 1957 to 1985 .

Methods - The following death certificates were obtained for the years 1981-4: those mentioning asthma (all age groups), chronic obstructive airway disease, emphysema, or chronic bronchitis, but only where the deceased was 55 years or less. Information was collected from medical records, questionnaires to the general practitioner, and interviews with a close relative of the deceased. Death as a result of asthma was confirmed or otherwise by a panel and the confirmed deaths were compared with those registered. The numbers of deaths from asthma for the years 1957-85 were obtained from the offices of the Northern Ireland Registrar General.
\end{abstract}

Results - A total of 174 deaths from asthma was identified; $123(70 \cdot 7 \%)$ had been registered, while the remainder had been coded under another diagnosis. The annual number of confirmed deaths differed little from the figures of the Registrar General. A sharp increase in the annual number of deaths from asthma was observed, beginning in 1977, following a decline in the mid 1970s.

Conclusions - During the years 1981-4 death certification for asthma was found to be inaccurate. The number of false positive registrations was balanced by the number of false negatives, suggesting that the registered totals reflect actual asthma mortality.

(Thorax 1994;49:141-143)

During the late 1970 s a dramatic increase in the numbers of deaths from asthma was reported from New Zealand. ${ }^{1}$ This increase was unexpected and occurred in all age groups. Many previous studies of death certification have concentrated on the younger age groups. ${ }^{23}$ We wanted to assess asthma mortality in all ages, and set out to investigate in detail each death in Northern Ireland between 1981 and 1984. We also examined deaths registered as chronic bronchitis, asthma, and chronic ob- structive airways disease where the deceased was 55 years or less, because we felt that this group might have included mislabelled deaths from asthma. In addition we aimed to assess the effect of the accuracy of registration on the registered totals of deaths from asthma in Northern Ireland from 1957 to 1985.

\section{Methods}

INVESTIGATION OF DEATHS

All death certificates issued in Northern Ireland during the years 1981-4 were examined with the permission of the Registrar General. All certificates where the diagnosis of asthma (ICD code 493) appeared, either in part 1 or in part 2 , were extracted. Certificates in which the main cause of death was ascribed to chronic bronchitis (ICD code 491, 466), emphysema (ICD code 492), or chronic obstructive airways disease (ICD code 496 or 519.8 ) were also obtained if the age of death was 55 years or less. The names, addresses, and dates of birth of these individuals were forwarded to the Central Services Agency (CSA) for Northern Ireland to which all general practitioners in the province are required to return the medical records of deceased patients. The CSA then made the records available for the study on the understanding that full medical confidentiality would be maintained. Ethical clearance was obtained from the medical adviser to the CSA and from the local medical committees which represent general practitioners in each of the four Northern Ireland Area Health Boards. We were unable to obtain the general practitioner records for those patients aged 55 years and under and registered as dying of chronic obstructive airways disease, chronic bronchitis, or emphysema in 1981; these were available only for the years 1982-4.

Records were obtained for $352(92 \%)$ of the 382 eligible cases dying between 1981 and 1984 and the relevant information regarding the diagnosis of asthma was recorded. Further information was obtained from the 13 necropsy reports supplied by the State Pathologist's office and from a number of hospital records $(53 \%)$. With the consent of the local medical committee a questionnaire was sent to the general practitioner of the deceased patients. The questions related to diagnosis, symptoms, drug treatment, and circumstances of death: $87 \%$ were returned completed. The general practitioner was also asked if he would agree to an interview of the closest relative or associate of the deceased. Two consultant respiratory physicians (JMacM, DGS) were then presented with details of the deceased's death 
certificate (by SCW) and, where available, the general practitioner's medical records, necropsy report, hospital records, and the questionnaire to the deceased's general practitioner. On the basis of this information they decided whether the patient had asthma and, if so, whether asthma was the cause of death. A diagnosis of asthma was accepted if both physicians agreed that one of the following three conditions was satisfied: (1) evidence of greater than $20 \%$ reversibility to airflow obstruction on pulmonary function testing; (2) pathological evidence of asthma at post mortem examination - that is, hyperinflated lungs with mucus plugging; (3) a typical history of asthma. In some cases it was clear that death was not caused by asthma. In cases where death was thought to be from asthma, or the two physicians were undecided or disagreed, further information was obtained by arranging to visit the closest relative or associate of the deceased. As a result of this screening 168 cases were not considered further and 184 were selected for further investigation. One of the authors (SCW) then carried out interveiws in 152 cases ( $83 \%$ ): 11 could not be traced and in 21 the general practitioner objected. A questionnaire was administered and details of asthmatic symptoms, drug treatment, and the circumstances of death were recorded. The two respiratory physicians then assessed the additional information in conjunction with the previous data and gave their final opinion. As a result of this further scrutiny, 10 deaths were considered not to be caused by asthma. A total of 174 cases was confirmed, including 32 in

Table 1 False positive and false negative registration of deaths from asthma by age group, 1982-4

\begin{tabular}{lcccc}
\hline $\begin{array}{l}\text { Age } \\
\text { (years) }\end{array}$ & $\begin{array}{l}\text { Total no. } \\
\text { registered }\end{array}$ & $\begin{array}{l}\text { Registered but not confirmed } \\
\text { (false positive) }\end{array}$ & $\begin{array}{l}\text { Not registered but confirmed } \\
\text { (false negative) }\end{array}$ & $\begin{array}{l}\text { Total no. } \\
\text { confirmed }\end{array}$ \\
\hline $0-44$ & 27 & $0(0)$ & $7(26)$ & 34 \\
$45-64$ & 57 & $11(19)$ & $26(46)$ & 72 \\
$65+$ & 62 & $40(64)$ & $17(27)$ & 39 \\
$\begin{array}{l}\text { All age } \\
\text { groups }\end{array}$ & 146 & $51(35)$ & $50(34)$ & 145 \\
\hline
\end{tabular}

Values in parentheses are percentages.

Table 2 Number of deaths from asthma registered by the Registrar General and number confirmed by the panel

\begin{tabular}{llllll}
\hline Year & $\begin{array}{l}\text { Total no. } \\
\text { registered }\end{array}$ & $\begin{array}{l}\text { No. registered and } \\
\text { confirmed by panel }\end{array}$ & $\begin{array}{l}\text { \% of total } \\
\text { registered }\end{array}$ & $\begin{array}{l}\text { No. not registered and } \\
\text { confirmed by panel }\end{array}$ & $\begin{array}{l}\text { Total no. confirmed } \\
\text { by panel }\end{array}$ \\
\hline 1981 & 44 & 29 & 66 & Not available & - \\
1982 & 47 & 30 & 64 & 15 & 45 \\
1983 & 54 & 35 & 65 & 21 & 56 \\
1984 & 45 & 30 & 67 & 14 & 44 \\
\hline
\end{tabular}

Figure 1 Distribution of deaths from asthma per 100000 of the total population, $1957-85$.

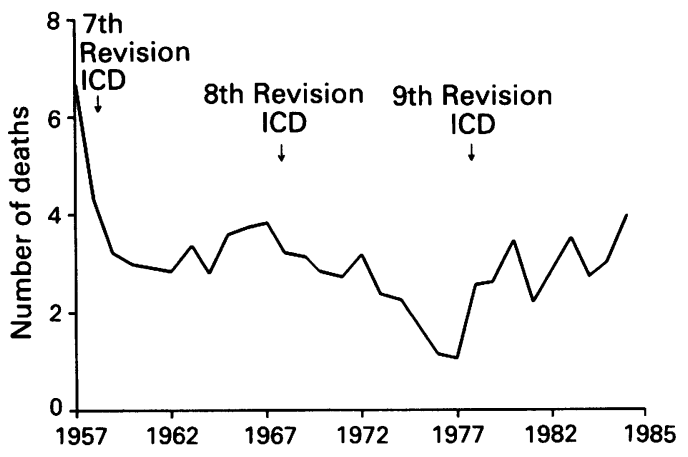

which an interview with a relative was not performed.

Details on the number and age of patients dying from asthma between 1957 and 1985 were obtained from the office of the Northern Ireland Registrar General. Mid year population estimates were also obtained so that both crude death rates and age specific deaths per 100000 population could be examined.

\section{Results}

\section{ACCURACY OF CERTIFICATION}

Of the 174 confirmed cases, $123(70 \cdot 7 \%)$ were originally registered as being due to asthma (59 men, 64 women). The remaining $51(29.3 \%)$ were coded under another diagnosis $(27$ men, 24 women). Table 1 shows the distribution of "false positive" and "false negative" registrations by age group. The "false positives" tended to come from those aged 65 years and over; the "false negatives" were more evenly spread over the three age groups with a preponderance in the 45-64 year age group. The general practitioners who completed the relevant sections of the questionnaire (138 cases) felt asthma was the cause of death in only 89 $(64.5 \%)$. They disagreed with the panel's diagnosis in 16 of the cases and did not know in 33. The certificates were completed in 41 cases by a hospital doctor of which nine were felt by the panel to be incorrect. General practitioners completed the certificates in 133 cases and the panel disagreed with $42(32 \%)$ of them.

DEATHS FROM ASTHMA AND CHRONIC AIRFLOW OBSTRUCTION

Table 2 shows the number of deaths from asthma registered each year by the Registrar General for the years 1981-4, along with those deaths confirmed by the panel in each year as being caused by asthma. Although death certification was inaccurate, the total number of deaths confirmed by the panel differed little from the total number registered. Figure 1 shows the number of deaths from asthma registered per 100000 population from 1957 to 1986 in all age groups. There was no difference in distribution by sex. Figure 2 shows the numbers of deaths in the three age groups. The number of registered cases fell after the seventh revision of ICD coding in 1958, which stated that deaths resulting from asthma which were indicated as being allergic or mentioned acute bronchitis were to be recorded as being due to bronchitis. The number of deaths rose from 1964 to 1971, peaking in 1967. The eighth revision of the ICD was implemented in 1968 and this extended the seventh revision guidelines by stating that if bronchitis, bronchiolitis, or emphysema was mentioned with asthma, then death should be attributed to one of the former conditions. The number of deaths rose again in 1978 in all age groups after a trough in 1977 and before the introduction of the ninth revision of the ICD in 1979. The death rate in the 5-44 age group showed a further decline between 1983 and 1985, but the 


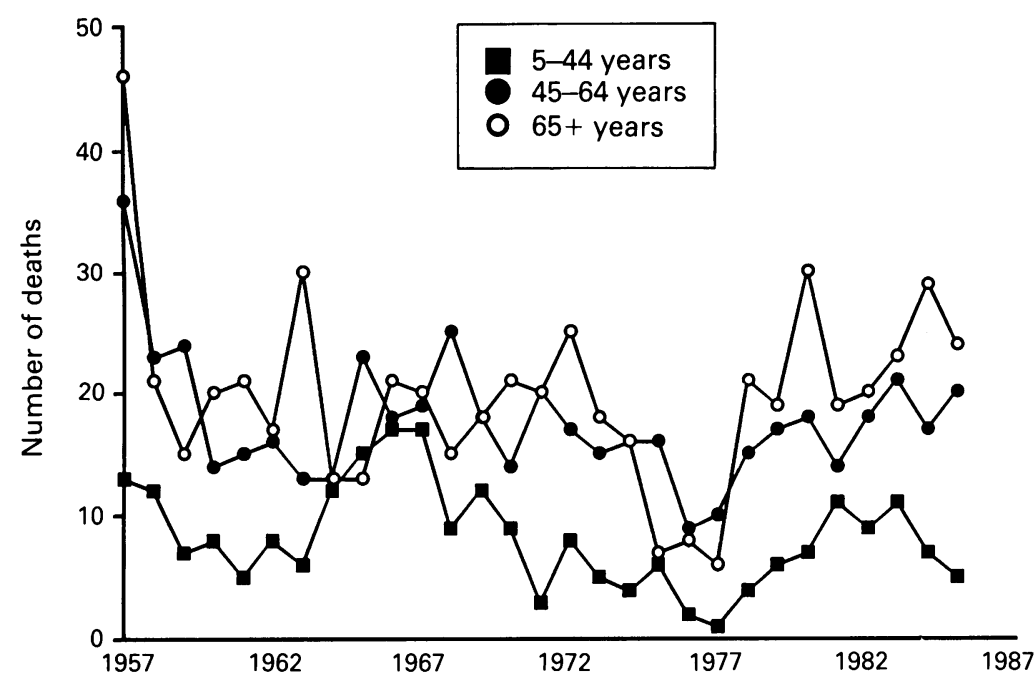

Figure 2 Distribution of deaths from asthma by age group, 1957-85.

number of deaths in this group is too small to determine a significant trend.

\section{Discussion}

This study has investigated the accuracy of asthma death certification in Northern Ireland between 1981 and 1984. All age groups were included. It was found that $35 \%$ of registered asthma deaths were inaccurate. Previous studies $^{4-6}$ have shown proportions of misdiagnosis ranging from $24 \%$ to $28 \%$. The higher proportion in our study may reflect the inclusion of older patients. The study, like many previously, can be criticised for the lack of a general practitioner on the assessment panel.

False negative certificates were often the result of medical factors in the certification process. Although $93 \%$ of the doctors knew the deceased patient had asthma, this was only reflected in the notified cause of death in $64.5 \%$ of confirmed cases. If death occurred acutely, the doctor was likely to certify death as being due to a vascular condition such as myocardial infarction or cerebrovascular disease - conditions commonly associated with sudden death. As was the case with the study by the British Thoracic Association ${ }^{4}$ and that by Ormerod and Stableforth, ${ }^{5}$ there was inconsistency in the labelling of different conditions manifesting as airflow obstruction. On the other hand, the cause of false positive certificates was often related to procedures in the Registrar General's office. Clerical officers are required to interpret each death certificate and apply an ICD code number. If the cause of death is not clear they would register what they considered to be the most appropriate diagnosis written anywhere on the certificate. Inaccurate registration may result since, if asthma is recorded anywhere on the death certificate, it may then be coded as the underlying cause of death. It is unlikely that this practice has changed sufficiently over the years to account for variations in registered asthma death rates.

During each of the years 1982-4 the number of false positive diagnoses approximately balanced the number of false negatives. The registered total therefore differed very little from the total confirmed by the panel. We feel that the registered figures over the period 195785 are likely to be reasonably accurate, apart from the caveat that we did not address the question of whether deaths from asthma in the over 55 age group might have been coded in one of the other categories of airflow obstruction. Both the registered figures and our confirmed totals may therefore be an underestimate.

Registered deaths from asthma in Northern Ireland increased in the 1960s and peaked in 1968. This increase appears to have occurred mainly in the 5-44 age group. During the same year there was a similar peak in the Republic of Ireland, ${ }^{7}$ but Ireland lagged two years behind the peak in England and Wales. ${ }^{8}$ From 1968 there was a pronounced fall in the death rate to a trough in 1977 when only 14 deaths were registered, followed by a further peak of 56 deaths in 1983 which affected all age groups. This rise occurred later than the rise in the number of deaths in New Zealand which started in 1976 and peaked in $1979 .{ }^{1}$ It also coincided with a rise in deaths from asthma in many other parts of the world. ${ }^{9}$ The mortality has decreased slightly since then but, up to and including the year 1986, still remains far above the 1977 level. We have therefore identified either two peaks in asthma deaths (in the 1960s and late 1970s) or one trough (in the mid 1970s). The changes in mortality cannot be explained by the introduction of the ninth revision of the ICD in 1979; the numbers had begun to increase before 1979 and the percentage rise far exceeded the $28 \%$ rise predicted by a bridge coding exercise, ${ }^{10}$ and indeed continued for several years after the introduction of the ninth revision.

In conclusion, we have shown that death certification for asthma is inaccurate in one third of cases. The number of false positive certificates was approximately equal to the number of false negatives, suggesting that the registered totals are reliable, although our study did not consider potential false negatives in the $>55$ age group. Deaths from asthma declined in the mid 1970s and rose sharply from 1977. The fluctuations in mortality are unlikely to be related to either changes in ICD coding practice or to inaccuracy of certification.

The authors wish to thank the Northern Ireland Chest, Heart and Stroke Association for providing secretarial assistance for this project.

1 Jackson RT, Beaglehole R, Rea HH, Sutherland DC. Mortality from asthma; a new epidemic in New Zealand. Lancet 1982;285:771-4.

2 Fraser P, Doll R. Geographic variations in the epidemic of asthma deaths. Br F Prev Soc Med 1971;25:34-6.

3 Speizer FE, Doll R. A century of asthma deaths in young people. BMF 1968;3:245-6.

4 British Thoracic Association. Death from asthma in two regions of England. BMF 1982;285:1251-5.

5 Ormerod LP, Stableforth DE. Asthma mortality in Birmingham 1975-7: 53 deaths. $B M \mathcal{F}$ 1980;280:687-90.

6 Sears MR, Rea HH, Beaglehole R, Gillies AJD, Holst PE, O'Donnell TV, et al. Asthma mortality in New Zealand. A two-year national study. NZ Med fु 1985;98:271-5.

7 Scott A. Report of a survey of deaths due to asthma in the Republic of Ireland. F Ir Med Assoc 1971;64:132-6.

8 Inman WHW, Adelstein AM. Rise and fall of asthma mortality in England and Wales in relation to use of

9 Sly RM. Increases in deaths from asthma. Ann Allergy 1984;53:20-5.

10 Klebba AJ, Scott JH. Estimates of selected comparability ratios based on dual coding of 1976 death certificates by the 8th and 9th revisions of the International Classification of Diseases. DHEW Publication No (PHS) 80-1120, Vol 28, No 11, Supplement: 1980 